\title{
Purdue University
}

\section{Purdue e-Pubs}

International Refrigeration and Air Conditioning

Conference

School of Mechanical Engineering

2000

\section{Simulation of the Performance of Alternative Refrigerants in Liquid Chillers}

\author{
I. N. Grace \\ Brunel University \\ S. A. Tassou \\ Brunel University
}

Follow this and additional works at: http://docs.lib.purdue.edu/iracc

Grace, I. N. and Tassou, S. A., "Simulation of the Performance of Alternative Refrigerants in Liquid Chillers" (2000). International Refrigeration and Air Conditioning Conference. Paper 513.

http://docs.lib.purdue.edu/iracc/513

This document has been made available through Purdue e-Pubs, a service of the Purdue University Libraries. Please contact epubs@purdue.edu for additional information.

Complete proceedings may be acquired in print and on CD-ROM directly from the Ray W. Herrick Laboratories at https://engineering.purdue.edu/ Herrick/Events/orderlit.html 


\title{
SIMULATION OF THE PERFORMANCE OF ALTERNATIVE REFRIGERANTS IN LIQUID CHILLERS
}

\author{
I N Grace, S A Tassou \\ Department of Mechanical Engineering \\ Brunel University \\ Uxbridge \\ Middlesex UB8 3PH \\ United Kingdom \\ Tel.: +(44) 1895274000 Ext. 2718 \\ Fax: +(44) 1895256392 \\ E-mail address: mesring@brunel.ac.uk
}

\begin{abstract}
The impact of man-made chemicals on the environment, and in particular, the ozone layer, has been investigated over the last 20 years. The phaseout of CFCs under European Regulations and the Montreal Protocol has already taken place and HCFCs are set to follow. A wide range of alternative refrigerants with zero ozone depletion potential have already been developed as replacements for the refrigeration industry. Mathematical modelling of refrigeration systems enables the performance of these alternatives to be evaluated across a broad range of operating conditions.

This paper investigates the simulated performance of a liquid chiller retrofitted with a range of alternative refrigerants. The mathematical model of the system is briefly outlined and the properties of the alternative refrigerants discussed. The performance of the system is determined in terms of cooling capacity, power consumption and coefficient of performance for a range of different operating conditions. The relative performance of each refrigerant is discussed and the preferred alternative identified for typical applications.
\end{abstract}

\section{INTRODUCTION}

Refrigeration and air-conditioning systems contribute both directly and indirectly to the problems of global warming and ozonc depletion. The impact of these systems on the environment can be reduccd by operating with less harmful refrigerant fluids and increased energy efficiency.

The world market for refrigerants has been dominated by the halogenated hydrocarbon chemical family. These chemicals are available at low cost and are highly stable with good thermophysical properties, low toxicity and compatibility with common lubricants (March Consulting Group, 1992). However, the stability of these materials also leads to a damaging effect on the stratospheric ozone layer when released into the environment.

A number of studies have detailed the steady-state performance of refrigeration systems with alternative refrigerants (Snelson et al., 1995, Linton et al., 1996). Domanski and Didion (1993) presented a performance evaluation of a number of alternative refrigerants operating in a residential heat pump using a steady-state model. The aim of the investigation presented here is to use a dynamic simulation model to investigate the steady-state and dynamic performance of chillers operating with R22 and alternative refrigerants. 


\section{MATHEMATICAL MODEL}

A dynamic simulation model of a liquid chiller was developed (Grace and Tassou, 2000). The system was modelled as four component models - the two heat exchangers, a semi-hermetic reciprocating compressor and a thermostatic expansion valve. The model was validated against data taken from an experimental test rig.

The heat exchangers were modelled as a number of discrete control volumes to which the fundamental conservation equations were applied. The equations were then integrated with respect to time and distance to produce the discretized form. The pressure was determined by an iterative method in which the calculated outlet mass flow rate was compared to a boundary condition.

The semi-hermetic reciprocating compressor was treated as a set of control regions to which the first law of thermodynamics was applied. These regions were modelled as lumped parameter volumes in which spatial variations were neglected. The compression process was simulated using the isentropic efficiency to account for irreversibilities. The compressor mass flow rate was calculated from the compressor speed, cylinder displacement and the volumetric efficiency.

The thermostatic expansion valve (TEV) was modelled by the application of the conservation of energy to various zones between the remote phial and the evaporator outlet. This provided an approximate value for the remote phial pressure acting on the valve diaphragm. A force balance on the diaphragm determined the position of the valve spindle and the orifice area. The mass flow rate through the valve was then calculated using the Bernoulli equation for flow through an orifice plate.

\section{ALTERNATIVE REFRIGERANTS TO R22}

Four alternative refrigerants to R22 were investigated; R404a, R507a, R407c and R134a. All the alternatives are suitable for operation across the full range of R22 applications, except R134a which has a normal boiling point of $-26.07^{\circ} \mathrm{C}$ (NIST Refprop Version 6.01, McLinden et al., 1998) and is not generally used in applications requiring refrigerant evaporating temperatures below $-20^{\circ} \mathrm{C}$. Table 1 shows some thermophysical properties of R22 and the alternative refrigerants.

Although all the alternative refrigerants feature zero Ozone Depletion Potential (ODP), it is interesting to note that R404a and R507a both possess considerably greater Global Warming Potential (GWP) than R22. R134a has a high critical temperature and normal boiling point and this leads to relatively low pressures in comparison to R22 and the other alternatives. This effectively limits R134a to applications with higher evaporating temperatures. R404a and R507a both have low critical temperatures and normal boiling points and this results in relatively high pressures in comparison to R22. R407c is a high temperature glide mixture and features normal boiling points and pressures which are similar to R22.

Comparison of the relative saturated vapour densities shows that R134a will deliver considerably lower mass flow rates than R22. The latent heat of R134a is similar to R22 and therefore this reduced mass flow rate will lead to lower cooling capacities. R407c possesses both vapour density and latent heat properties which are very similar to $R 22$ and consequently cooling capacities will be close to those for R22. R404a and R507a display large vapour densities relative to R22. However, both refrigerants also feature reduced latent heats which act to limit any potential gains in cooling capacity delivered by increased mass flow rates. 
Table 1 Thermophysical properties of refrigerants

\begin{tabular}{|c|c|c|c|c|c|}
\hline Refrigerant & $\mathbf{R 2 2}$ & R134a & R407c & R404a & R507a \\
\hline Components & $\mathrm{R} 22$ & RI34a & $\begin{array}{c}\mathrm{R} 32 / 125 / \\
134 \mathrm{a}\end{array}$ & $\begin{array}{c}\mathrm{R} 125 / 143 \mathrm{a} / \\
134 \mathrm{a}\end{array}$ & $\mathrm{R} 125 / 143 \mathrm{a}$ \\
\hline $\begin{array}{c}\text { Composition } \\
\text { (by mass percentage) }\end{array}$ & 100 & 100 & $23 / 25 / 52$ & $44 / 52 / 4$ & $50 / 50$ \\
\hline Fluorocarbon type & HCFC & HFC & HFC & HFC & $\overline{\mathrm{HFC}}$ \\
\hline $\begin{array}{l}\text { Global Warming } \\
\text { Potential }^{1,2} \text { (GWP) }\end{array}$ & 1500 & 1300 & 1520 & 3260 & 3300 \\
\hline $\begin{array}{l}\text { Ozone Depletion } \\
\text { Potential }^{3} \text { (ODP) }\end{array}$ & 0.04 & 0 & 0 & 0 & 0 \\
\hline $\begin{array}{l}\text { Critical temperature } \\
{\left[{ }^{\circ} \mathrm{C}\right]}\end{array}$ & 96.15 & 101.06 & 86.05 & 72.14 & 70.75 \\
\hline $\begin{array}{c}\text { Boiling point }{ }^{4}\left[{ }^{\circ} \mathrm{C}\right] \\
\text { (bp-bubble point) } \\
\text { (dp-dew point) }\end{array}$ & -40.81 & -26.07 & $\begin{array}{l}-43.81 b p \\
-36.73 d p\end{array}$ & $\begin{array}{l}-46.57 b p \\
-45.79 d p\end{array}$ & $\begin{array}{l}-47.11 b p \\
-47.11 d p\end{array}$ \\
\hline $\begin{array}{l}\text { Density of saturated } \\
\text { vapour }\left[\mathrm{kg} / \mathrm{m}^{3}\right] \\
\text { (at dew point) }\end{array}$ & 44.23 & 32.35 & 43.76 & $65 . \overline{32}$ & 68.98 \\
\hline $\begin{array}{l}\text { Bubble point } \\
\text { pressure }^{5} \text { [bar] }\end{array}$ & 10.44 & 6.65 & 11.88 & 12.60 & 12.88 \\
\hline $\begin{array}{c}\text { Dew point pressure } \\
\text { [bar] }\end{array}$ & 10.44 & 6.65 & 10.19 & 12.46 & 12.87 \\
\hline $\begin{array}{c}\text { Temperature glide }{ }^{4,6} \\
{\left[{ }^{\circ} \mathrm{C}\right]}\end{array}$ & 0 & 0 & 7.08 & 0.78 & 0 \\
\hline $\begin{array}{c}\text { Latent heat }^{5,7} \\
{[\mathrm{~kJ} / \mathrm{kg}]}\end{array}$ & 182.7 & $17 \overline{77.8}$ & 183.0 & 140.0 & 136.2 \\
\hline \multicolumn{6}{|c|}{$\begin{array}{l}\text { All data NIST REFPROP V6.01 (McLinden et al., 1998) except where noted, } \\
\begin{array}{ll}\text { 1. International Institute of Refrigeration (1997), } & 5 . \text { At } 25^{\circ} \mathrm{C} \text {, } \\
\text { 2. GWP based on } 100 \text { year time-horizon, } & 6 . \text { Temperature glide }=\text { Dew point }- \text { Bubble point, } \\
\text { 3. ARTI (1998), } & \text { 7. Enthalpy }=0 \text { for sat.liquid at }-40^{\circ} \mathrm{C} \text { (ASHRAE), } \\
\text { 4. At } 1.013 \text { bar, } & \end{array}\end{array}$} \\
\hline
\end{tabular}

\section{SYSTEM PERFORMANCE}

The performance of the system using a number of alternative refrigerants to R22 was investigated. The results using R22 were used to provide baseline performance data and these were then compared to results for refrigerants R407c, R404a, R507a and R134a. The operating conditions were selected to allow examination of the relative performance of refrigerants in two application areas; high temperature refrigeration, characterised by refrigerant evaporating temperatures in the region of $-10^{\circ} \mathrm{C}$, and air-conditioning, with a typical evaporating temperature of $0^{\circ} \mathrm{C}$. Simulations for $\mathrm{R} 134 \mathrm{a}$ were restricted to evaporator coolant temperatures equal to or above $0^{\circ} \mathrm{C}$ due to its high normal boiling point. 


\section{Cooling capacity}

The system cooling capacity for all five refrigerants across a range of evaporator temperatures at a condenser coolant outlet temperatures of $30^{\circ} \mathrm{C}$ and $40^{\circ} \mathrm{C}$ are shown in Figures 1 and 2. For R134a, the curves show the system with a retro-fitted compressor delivering twice the volumetric flow rate. This increases the system mass flow rate and enables comparison of $\mathrm{R} 134 \mathrm{a}$ at approximately the same cooling capacity as the other refrigerants.

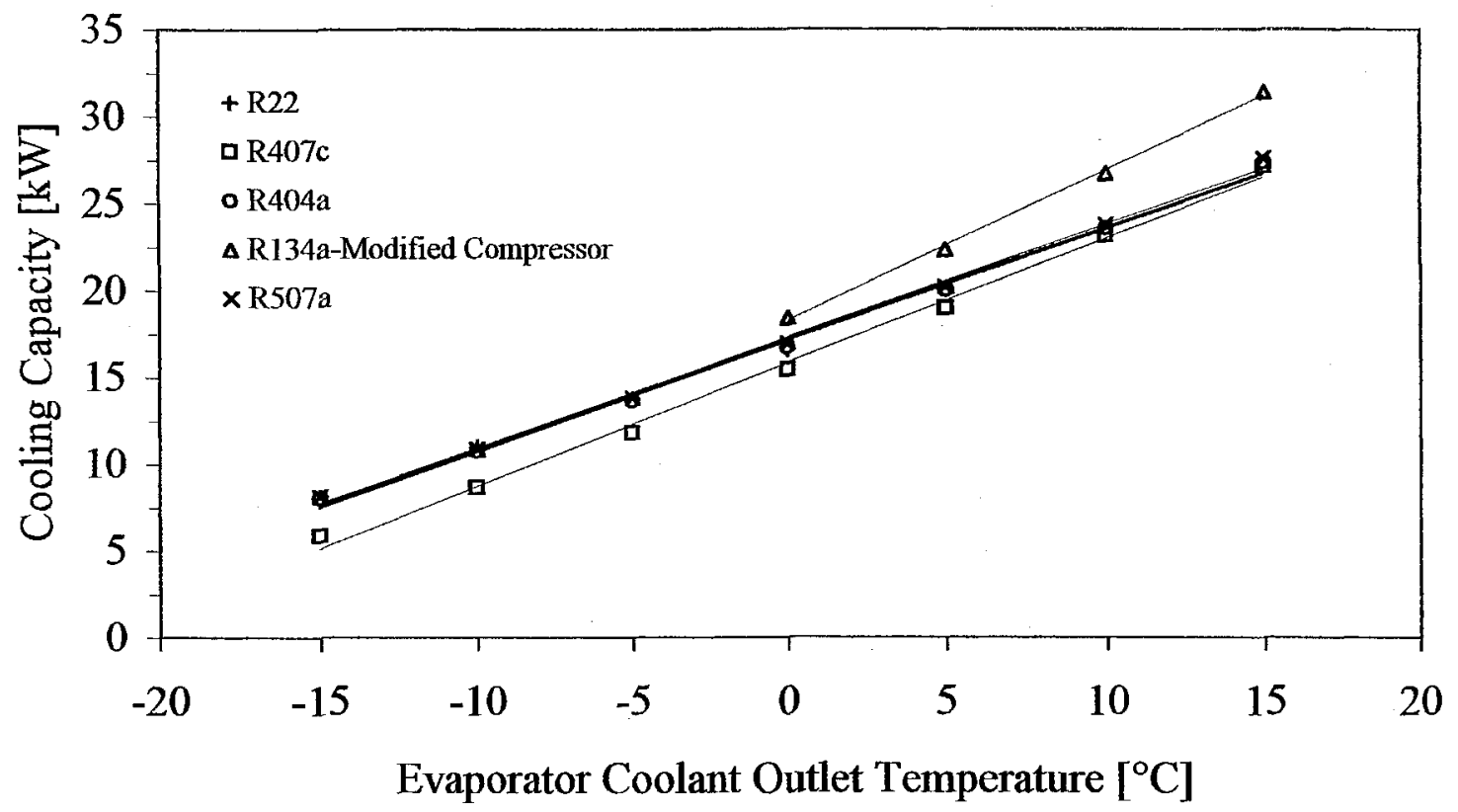

Figure 1 Cooling capacity at condenser coolant outlet temperature of $30^{\circ} \mathrm{C}$

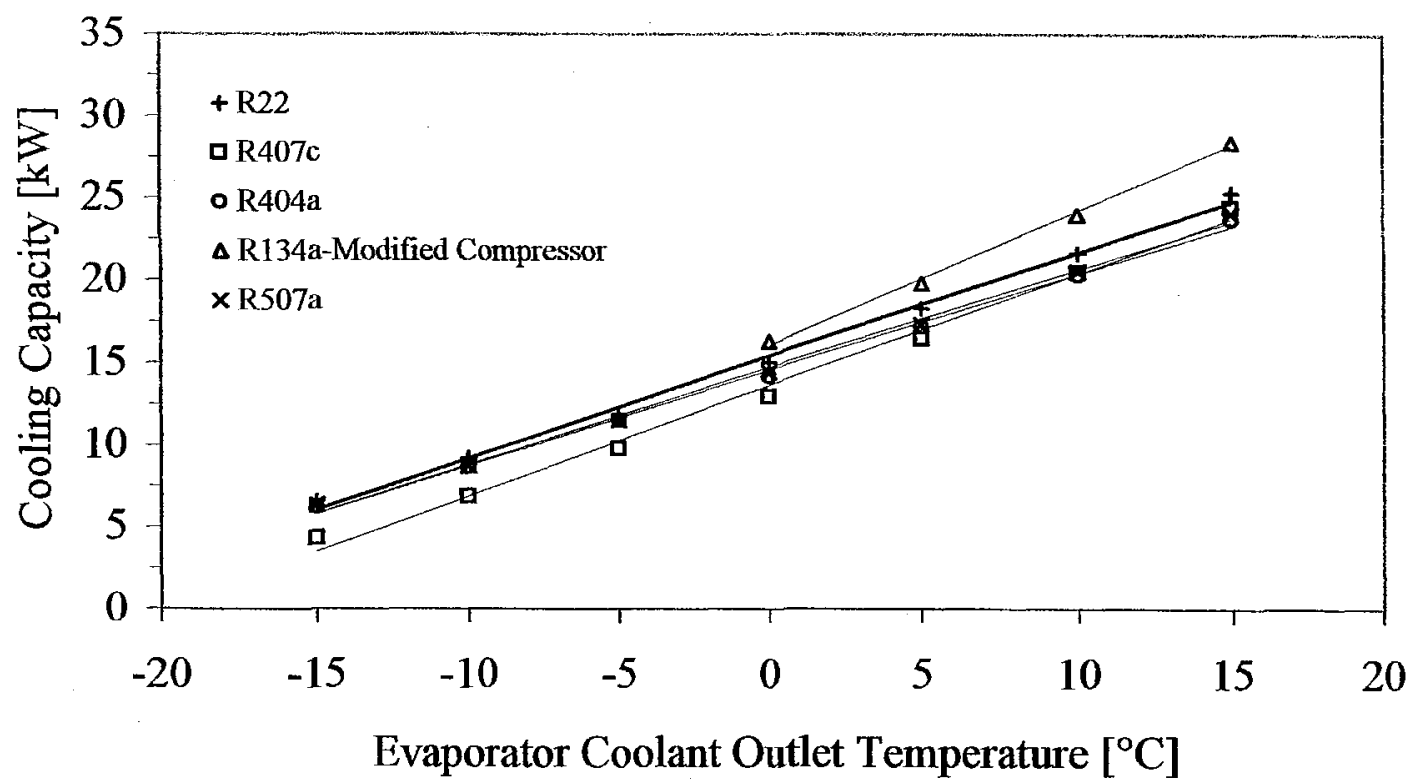

Figure 2 Cooling capacity at condenser coolant outlet temperature of $40^{\circ} \mathrm{C}$ 
All refrigerants display a linear increase in cooling capacity with evaporator coolant outlet temperature and a decrease with increasing condenser temperature. This is due to the increase in system mass flow rate and the increase in condenser pressure respectively.

The cooling capacity for R134a using the larger compressor is approximately $8 \%$ to $15 \%$ greater than that for R22 with the original compressor. This is attributable to the larger displacement of the replacement compressor which leads to a higher system mass flow rate for R134a. R407c generates between $65 \%$ and $99 \%$ of the R22 capacity, with the lower relative performance at lower evaporator and higher condenser temperatures.

R404a produces cooling capacities in the range $93 \%$ to $101 \%$ of $\mathrm{R} 22$. The maximum values are found at the lowest condenser temperature of $30^{\circ} \mathrm{C}$. There is no significant variation in the performance relative to $\mathrm{R} 22$ at different evaporator temperatures and, generally, R404a produces cooling capacities which are slightly lower than R22. R507a displays cooling capacity performance similar to that for R404a but with slightly larger cooling capacities across the full range of evaporator outlet temperatures. Cooling capacities are between $94 \%$ and $102 \%$ of $R 22$ for condenser temperatures of $30^{\circ} \mathrm{C}$ to $40^{\circ} \mathrm{C}$.

\section{Power consumption}

The compressor power consumption for condenser coolant outlet temperatures of $30^{\circ} \mathrm{C}$ and $40^{\circ} \mathrm{C}$ are shown in Figures 3 and 4 . The power consumption is shown to increase linearly with evaporator coolant outlet temperature and increased condenser temperature due to increased mass flow rate and pressure ratio respectively.

$\mathrm{R} 134 \mathrm{a}$ generates power consumption in the range $123 \%$ to $140 \%$ that for $\mathrm{R} 22$, using a compressor with twice the volumetric displacement. Refrigerant R407c produces power consumption in the range $91 \%$ to $105 \%$ of $\mathrm{R} 22$. The power consumption for a system charged with $\mathrm{R} 404 \mathrm{a}$ is greater than R22 for all operating conditions tested, ranging from $109 \%$ to $127 \%$ that of R22. The power consumption for R507a is generally in the range of $115 \%$ to $120 \%$ that of R22 with a minimum of $114 \%$ and a maximum of $121 \%$.

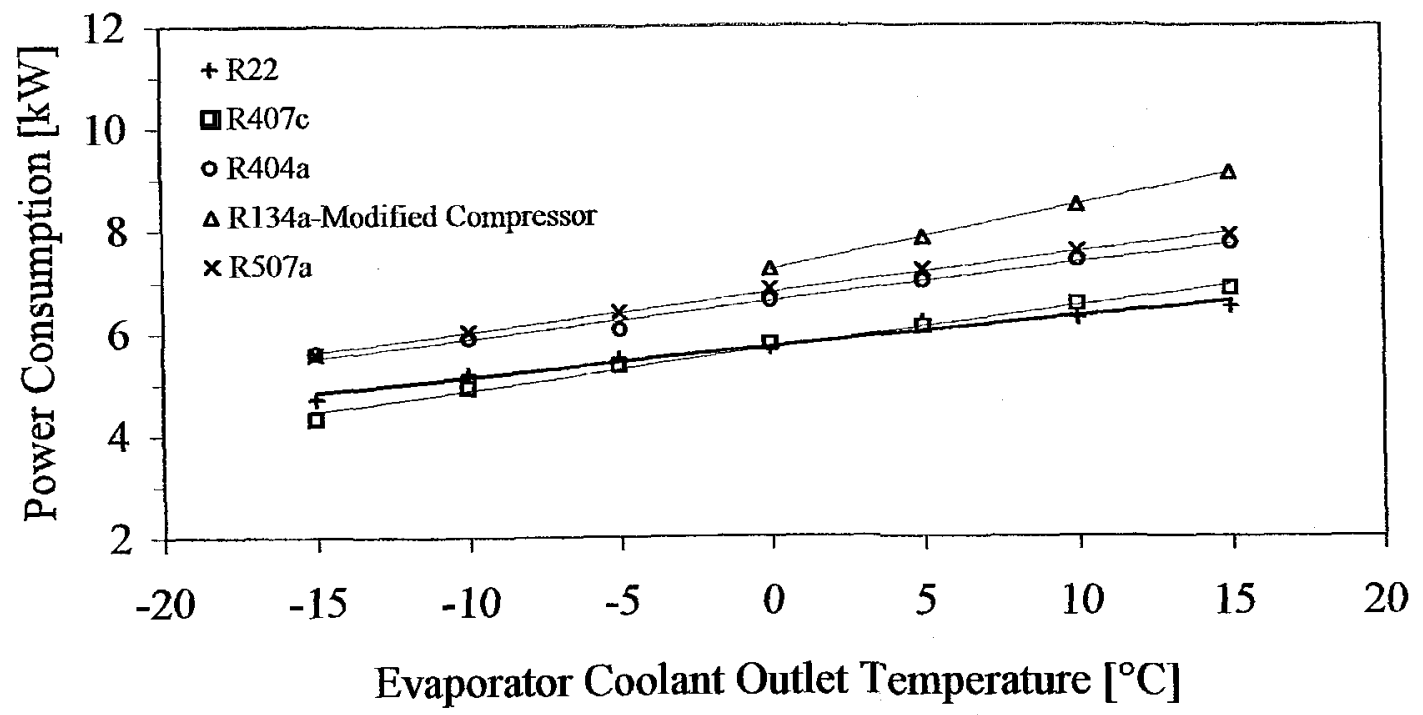

Figure 3 Power consumption at condenser coolant outlet temperature of $30^{\circ} \mathrm{C}$ 


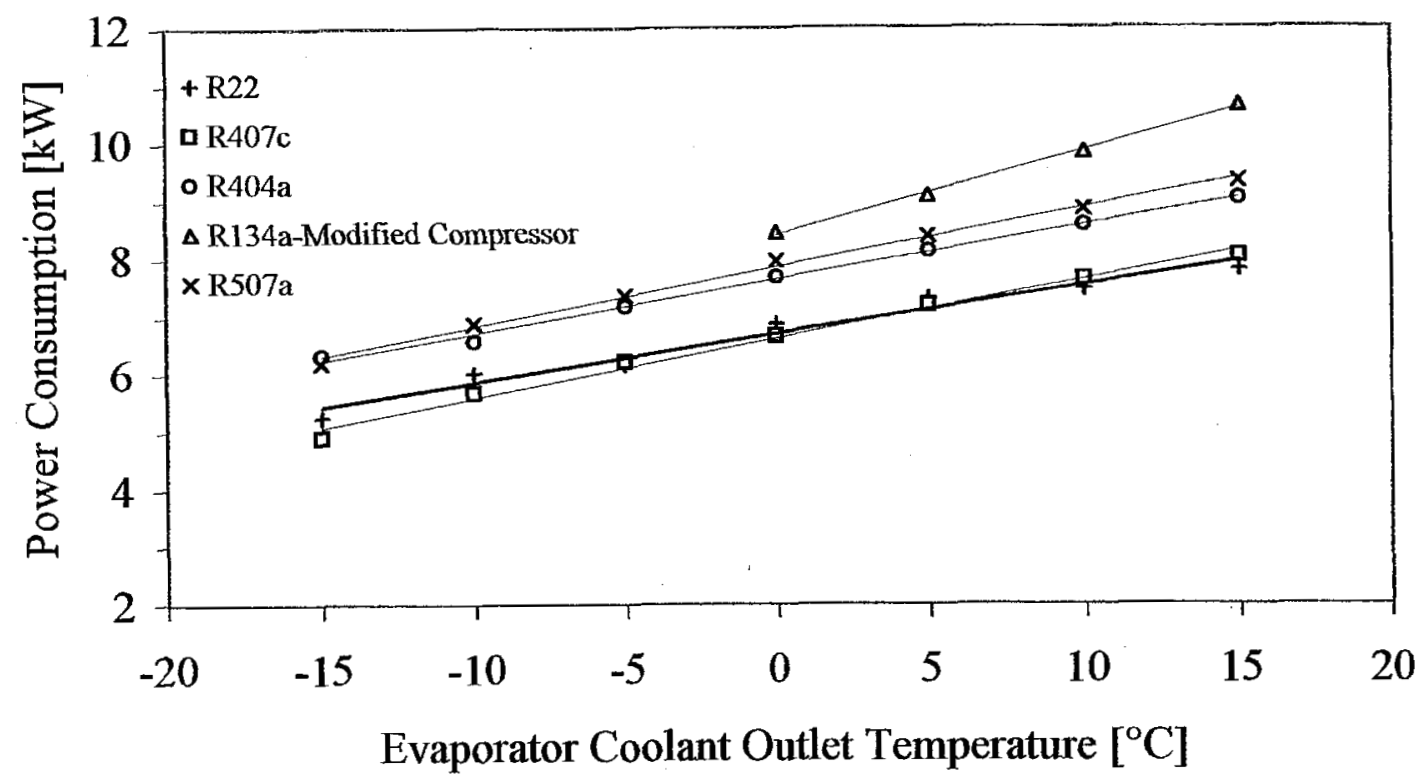

Figure 4 Power consumption at condenser coolant outlet temperature of $40^{\circ} \mathrm{C}$

\section{Coefficient of performance}

Figures 5 and 6 show the system coefficient of performance (COP). The COP is shown to increase linearly with evaporator outlet temperature and decrease as the condenser temperature is increased due to the resulting change in the pressure ratio.

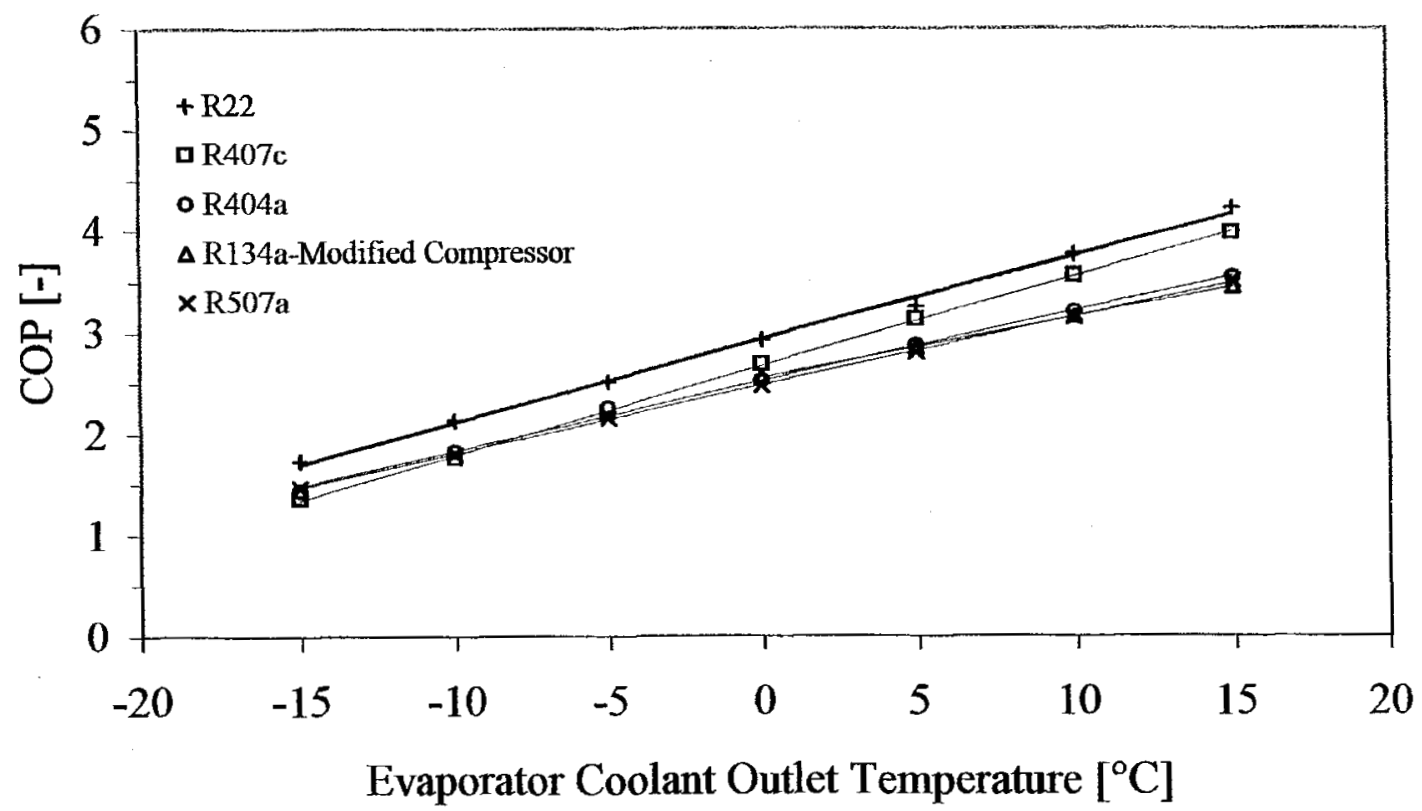

Figure $5 \mathrm{COP}$ at condenser coolant outlet temperature of $30^{\circ} \mathrm{C}$ 


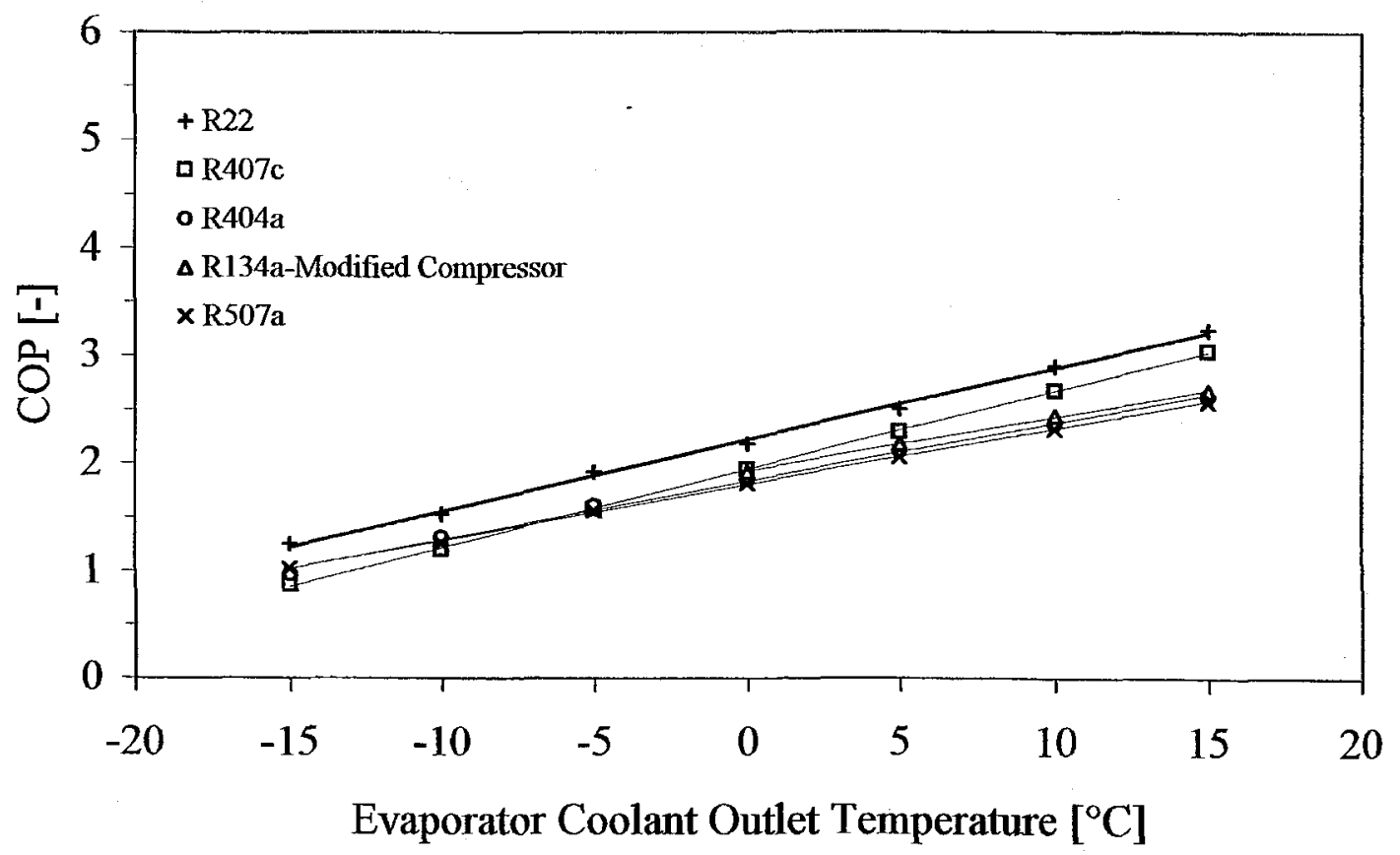

Figure $6 \mathrm{COP}$ at condenser coolant outlet temperature of $40^{\circ} \mathrm{C}$

The COP of $\mathrm{R} 134 \mathrm{a}$ ranges from $82 \%$ to $89 \%$ that of $\mathrm{R} 22$ for the system using the compressor with double the volumetric capacity. R407c produces COP's in the range $70 \%$ to $95 \%$ of R22, with higher values at higher evaporator temperatures. R404a delivers COP's between $78 \%$ and $90 \%$ of R22. Refrigerant R507a has similar performance to R404a with COP's in the range $79 \%$ to $86 \%$ of R22. There is a slight increase in COP with reduced condenser temperatures, as for R407c and R404a.

\section{CONCLUSIONS}

A series of steady-state performance simulations were carried out for a range of refrigerants. The results show that the cooling capacity of R22 is greater than that of the alternative refrigerants, with the exception of R134a which requires a larger displacement compressor. The alternative refrigerants generally require more power than R22 although R407c consumes marginally less power at low evaporator temperatures. Refrigerant R22 displays the highest COP with all the alternatives producing significantly lower values.

It can be concluded that, for typical air-conditioning applications, R407c is the preferred alternative to R22, with R134a an option at lower evaporating temperatures, although this would require a replacement compressor in order to produce comparable cooling capacities. R407c has a high glide temperature which can lead to composition changes after leakage and may require some valve adjustment.

For high temperature refrigeration, R404a and R507a both outperform R407c and these are the preferred refrigerants. There is little performance difference between R404a and R507a over this temperature range. Both R404a and R507a generate higher condenser pressures than R22 and this may require some modifications to existing equipment. 


\section{REFERENCES}

Domanski, P.A. and Didion, D.A., 1993. Thermodynamic evaluation of R22 alternative refrigerants and refrigerant mixtures, ASHRAE Transactions, 1993, Vol.99, Pt.2, pp.636-648.

Grace, I.N. and Tassou, S.A., 2000. Dynamic simulation of liquid chillers, 2000 International Refrigeration Conference at Purdue, Purdue University, West Lafayette, Indiana, USA.

Linton, J.W., Snelson, W.K., Hearty, P.F., Triebe, A.R., Murphy, F.T., Low, R.E. and Gilbert, B.E. 1996. Comparison of R407c and R4IOa with $R 22$ in a $10.5 \mathrm{~kW}$ (3.0TR) residential central heat pump, 1996 International Refrigerants Conference at Purdue, Purdue University, West Lafayette, Indiana, USA, pp.1-6.

March Consulting Group, 1992. CFC's in the UK refrigeration and air conditioning industries, HMSO, London, UK.

McLinden, M.O., Klein, S.A., Lemmon, E.W. and Peskin, A.P. 1998. NIST Thermodynamic and transport properties of refrigerants and refrigerant mixtures - REFPROP Version 6.01, National Institute of Standards and Technology, US Department of Commerce, Maryland, USA.

Snelson, W.K., Linton, J.W., Triebe, A.R. and Hearty, P.F. 1995. System drop-in tests of refrigerant blend RI25/RI 43a/R134a (44\%/52\%/4\%) compared to R502, ASHRAE Transactions, 1995, Vol.101, Pt.1, pp.17-24. 